\title{
Does coping mediate the relationship between competitive anxiety and eating disorders in athletes?
}

\author{
Leonardo de S. Fortes ${ }^{1}$ \\ (iD) https://orcid.org/0000-0002-0778-769X \\ José Roberto A. do Nascimento Junior ${ }^{2}$ \\ (iD) https://orcid.org/000o-0003-3836-6967 \\ Gabriel Lucas M. Freire ${ }^{2}$ \\ (iD) https://orcid.org/0000-0003-0589-9003 \\ Maria Elisa C. Ferreira ${ }^{3}$ \\ https://orcid.org/000o-0002-3294-7560
}

How to cite this article: Fortes, L. S., Nascimento, J. R. A, Junior, Freire, G. L. M., \& Ferreira, M. E. C. (2020). Does Coping coping mediate the relationship between competitive anxiety and eating disorders in athletes? Psicologia: Teoria e Prática, 22(3), 74-91. doi:10.5935/1980-6906/psicologia.v22n3p74-91

Submission: 09/18/2019

Acceptance: 06/25/2020

1 Federal University of Paraíba (UFPB), João Pessoa, PB, Brazil.

2 Federal University of Vale do São Francisco (UNIVASF), Petrolina, PE, Brazil.

3 Federal University of Juiz de Fora (UFJF), Juiz de Fora, MG, Brazil. 


\begin{abstract}
The competitive anxiety shows positive and linear relationship with risk behaviors for eating disorders (RBED). The competitive anxiety shows negative and linear relationship with coping strategies. Perhaps the coping strategies can mediate the relationship between competitive anxiety and RBED in athletes. The aim of this study was to analyze the coping mediation between competitive anxiety and RBED in Brazilian male athletes. 739 athletes from various sports participated. To assess the RBED frequency, the Disordered Eating in Sports Scale was adopted. The Brazilian version of the Competitive State Anxiety Inventory was used to evaluate competitive anxiety. Athletic Coping Strategies Inventory was used to evaluate coping strategies. The findings revealed a direct relationship between competitive anxiety and RBED $(p=.01)$. The results indicated that coping strategies potentiated the relationship between competitive anxiety and RBED $(p=.01)$. It was concluded that coping can be considered a psychological determinant in the relationship between competitive anxiety and RBED.
\end{abstract}

Keywords: sport psychology; anxiety; athletes; eating disorders; pathological behavior.

\title{
COPING MEDEIA A RELAÇÃO ENTRE ANSIEDADE COMPETITIVA E TRANSTORNOS ALIMENTARES EM ATLETAS?
}

\begin{abstract}
Resumo
A ansiedade competitiva possui relação positiva e linear com a frequência de comportamentos de risco para os transtornos alimentares (CRTA). A ansiedade competitiva apresenta relação negativa e linear com as estratégias de coping. Talvez o coping possa mediar a relação entre a ansiedade competitiva e a frequência de CRTA em atletas. O objetivo do estudo foi analisar a mediação do coping entre a ansiedade competitiva e os CRTA em atletas brasileiros do sexo masculino. Participaram 739 atletas. Para avaliação da frequência de CRTA, foi adotada a Disordered Eating in Sports Scale. Utilizou-se a versão brasileira do Competitive State Anxiety Inventory (CSAI-2R) para avaliar a ansiedade competitiva. Foi utilizado o Athletic Coping Strategies Inventory para avaliar as estratégias de coping. Os achados revelaram relação direta entre a ansiedade competitiva e os CRTA $(p=.01)$. Os resultados indicaram que as estratégias de coping potencializaram a relação entre a ansiedade competitiva e os CRTA $(p=.01)$. Concluiu-se que o coping pode ser considerado
\end{abstract}


uma variável psicológica determinante na relação entre a ansiedade competitiva e os CRTA.

Palavras-chave: psicologia do esporte; ansiedade; atletas; transtornos alimentares; comportamentos patológicos.

\title{
COPING MEDIA LA RELACIÓN ENTRE LA ANSIEDAD COMPETITIVA Y LOS TRASTORNOS DE LA ALIMENTACIÓN EN LOS ATLETAS?
}

\begin{abstract}
Resumen
No se sabe si el afrontamiento media la relación entre la ansiedad y los comportamientos de riesgo para los trastornos de la alimentación (CRTA) en atletas. El objetivo del estudio fue analizar la mediación de afrontamiento entre la ansiedad competitiva y CRTA en los atletas masculinos brasileños. Participaron 739 atletas. Para evaluar la frecuencia de los CRTA se adoptó Disordered Eating in Sports Scale. Se utilizó la versión brasileña del Competitive State Anxiety Inventory para evaluar la ansiedad competitiva. Se utilizó el Athletic Coping Strategies Inventory para evaluar las estrategias de afrontamiento. Los resultados revelaron una relación directa entre la ansiedad competitiva y CRTA $(p=.01)$. Los resultados indicaron que las estrategias de afrontamiento potenciaron la relación entre la ansiedad competitiva y CRTA ( $p=$ .01). Se concluyó que el afrontamiento se puede considerar una variable psicológica decisiva en la relación entre la ansiedad competitiva y CRTA.

Palabras clave: psicología del deporte; ansiedad; atletas; trastornos de la alimentación; comportamiento patológico.
\end{abstract}

\section{Introduction}

Behaviors that cause the risk of eating disorders consist of unhealthy methods for reducing body mass (Papathomas \& Petrie, 2014). Long periods without food intake, the use of laxative/diuretic/appetite suppressants, wearing plastic clothes to generate dehydration during physical training sessions, and self-induced vomiting are seen as the main risk behaviors for eating disorders (RBED) among athletes (Chapman \& Woodman, 2016). Scientific findings have shown that about 20\% of male athletes adopt RBED as a measure to enhance sports performance (Filaire, Rouveix, Pannafieux, \& Ferrand, 2007; Gapin \& Petruzzello, 2011), since coaches usually associate body mass reduction with improved competitive performance (Durguerian et al., 2016). 
In 2007, Petrie and Greenleaf created a theoretical model regarding the etiology of RBED in athletes, which postulates predictor variables of RBED (e.g., internalization of the athletic body ideal, dissatisfaction with body image and sociocultural pressures). Since then, some researchers have sought to confirm this theoretical model (Gomes, Martins, \& Silva, 2011; Krentz \& Warschburger, 2013; Peden, Stiles, Vandehey, \& Diekhoff, 2008; Scoffier, Maiano, \& D'Arripe-Longueville, 2010), whereas others have found controversial results (Filaire et al., 2007; Haase, 2011; Michou \& Costarelli, 2011). It indicates the need to develop a new model that could better explain the triggering of RBED in male athletes. In this sense, considering the inconsistency of Petrie and Greenleaf's model (2007), Fortes, Ferreira, Oliveira, Cyrino and Almeida (2015) tried to create a socio-sports model to explain more efficiently the etiology of RBED in Brazilian athletes. Fortes, Ferreira, Oliveira, Cyrino, and Almeida (2015) proposed that the concern with muscle tone and dissatisfaction with body fat could mediate the relationship between training regimen, competitive level, fat percentage, socio-cultural factors (sport pressures), and RBED in male athletes. However, these variables explained less than $20 \%$ of the RBED variance, and few of them (e.g., socio-cultural factors and dissatisfaction with body fat) did not adhere to the proposed model. These results show the importance of looking for other variables to get a better understanding of RBED in athletes. It is worth mentioning that neither of the above models included competitive anxiety.

Competitive anxiety is pointed out as a multifactorial construct regarding the willingness to respond to stress and as a tendency to perceive stressful situations (Fernandes, Nunes, Raposo-Vasconcelos, Fernandes, \& Brustad, 2013). According to the Multidimensional Theory of Competitive State Anxiety (Martens, Vealey, \& Burton, 1990), anxiety has three components: cognitive, somatic and self-confidence. Cognitive anxiety refers to negative thoughts and expectations regarding performance. Somatic anxiety is related to affective and physiological elements of an anxiety experience that directly affects the autonomic nervous system. Self-confidence means the conviction and feeling of ability to perform actions required in a competition. Although studies have shown a significant and linear relationship between competitive anxiety and RBED in athletes (Fortes, Almeida, \& Ferreira, 2014; Vardar, Vardar, \& Kurt, 2007), some sport scientists (Chapman \& Woodman, 2016; Thompson \& Sherman, 2014) claim that coping strategies can mediate such a relationship. For those authors, several factors 
prevent the development of RBED in athletes. Coping strategies, as an example, are an important cognitive and behavioral resource that can be used in stress situations to avoid the adoption of RBED.

For Serpa and Palmeira (1997), coping refers to cognitive and behavioral strategies to confront or avoid a stressful event such as a competition, in the specific case of athletes (Fernandes et al., 2013). Kurimay, Pope-Rhodius and Kondric (2017) demonstrated a close relationship between coping strategies and anxiety. The findings of Pons, Viladrich, Ramis and Polman (2018) indicated that coping strategies mediated the relationship between competitive anxiety and adaptive behaviors (e.g., commitment to sport). Wadey et al. (2014), in turn, affirmed that coping mediated the relationship between competitive anxiety and negative emotions (e.g. fear of injury) in amateur male athletes. However, it is essential to emphasize that, although coping can mediate the relationship between competitive anxiety and maladaptive emotions or behaviours (e.g., RBED), to the best of our knowledge, there is no study that has sought to analyze the relationship between coping and RBED in athletes. Therefore, it is necessary to conduct some research to ascertain whether the notes of Chapman and Woodman (2016), and Thompson and Sherman (2014) are consistent.

From a practical point of view, this type of research may reveal the relationship between competitive anxiety, coping strategies and RBED in Brazilian male athletes, whose results will be important for sports professionals. Based on this information, the purpose of this study was to carry out this type of investigation, that is, to analyze the mediation of coping between competitive anxiety and RBED in Brazilian male athletes. Considering observations of sport scientists (Chapman \& Woodman, 2016; Thompson \& Sherman, 2014), our hypothesis is that coping strategies mediate the relationship between competitive anxiety and RBED in male athletes.

\section{Method}

\subsection{Participants}

The participants of this study were professional and amateur Brazilian athletes, aged 15 years or more. A priori, sample calculation was done using Power 6.0 software, adopting a prevalence of $50 \%$ for RBED in Brazilian athletes, with $1 \%$ 
margin of error and 5\% confidence level. The minimum number of 469 athletes was identified, so that the findings could be inferred for the sample. Considering the sample losses from other investigations (Fortes, Kakeshita, Gomes, Almeida, \& Ferreira, 2014; Fortes et al., 2015), we decided to add the percentage of 20\%. Thus, the number of 560 athletes was adopted as the minimum sample size to be used since the minimum number of participants to conduct the structural equation model is 200 subjects (Fortes et al., 2015).

To include athletes in this investigation, the following criteria were adopted: 1. to practice their respective modality systematically with a minimum training of eight hours per week; 2 . to have had a minimum participation in a competition of regional dimension in 2016; and 3 . to be available to answer questionnaires and participate in anthropometric evaluations. The criteria for athletes' exclusion were: 1. to present physical or intellectual disability (informed by the coach); and 2. to have taken psychoactive medications in the six months prior to the research (informed by the athlete himself).

The athletes were selected in a non-probabilistic way, using the casualsimple technique, and they were approached at their own training site. Initially, it was possible to include 836 male athletes, but, later, 97 athletes were excluded for not having answered the questionnaires completely and/or not having taken part in the measurement of anthropometric measures. The final number of athletes investigated was 739 , aged $18,15 \pm 1.68$ years old - athletics $(n=17)$; basketball ( $n=58)$; boxing $(n=11)$; canoing $(n=13)$; cycling $(n=27)$; football $(n$ =95); handball $(n=54)$; jiu-jitsu $(n=42)$; judo $(n=52)$; Olympic weightlifting $(n=9)$; swimming $(n=146)$; water polo $(n=22)$; rowing $(n=18)$; ornamental jumping $(n=11)$; tae-kwon-do $(n=30)$; tennis $(n=8)$; triathlon $(n=11)$, sailing ( $n=10)$, volleyball $(n=89)$, and beach volleyball $(n=16)$. All of the athletes participated in clubs in ten Brazilian states: Ceará $(n=46)$; Mato Grosso do Sul ( $n$ 28); Minas Gerais $(n=103)$; Pará $(n=21)$; Paraíba $(n=71)$; Pernambuco $(n=$ 116); Paraná ( $n=45)$; Rio de Janeiro $(n=100)$; Rio Grande do Sul ( $n=49)$; and São Paulo $(n=160)$.

\subsection{Measurements}

- RBED: the Eating Disorder Diagnostic Scale (EDDS) questionnaire, built and validated for Portuguese language (Fortes, Almeida, \& Ferreira, 2016), was 
adopted to evaluate the frequency of RBED. The questionnaire consists of 21 questions in a five-point Likert scale ( $0=$ never; $1=$ almost never; $2=$ sometimes; 3 = many times; 4 = always). These scales are divided into five subscales: 1. eating compulsion in the sports environment (e.g. "I think my coach would like me to be thin"); 2. eating restriction and body weight reduction (e.g. "I wear warm/plastic clothes during training to lose weight"); 3. healthy eating behavior in sports environment (e.g. "I think my diet is appropriate to improve my performance in competitions"); 4. use of substances/drugs and food satiety in sport (e.g. "I take laxatives, and/or diuretics before competitions to lose weight"); 5. behaviors and cognitions aimed at increasing muscle mass/performance (e.g. "After training, I eat an amount of food that satiates $m e$ "). The higher the score, the higher the frequency of RBED. It should be noted that items in subscales 3 and 4 have inverted scores ( $4=$ never; $3=$ rarely; 2 = sometimes; 2 = almost always; 1 = always). In the original validation study, the internal consistency achieved was .74 for EDDS (Fortes, Almeida et al., 2016). For the present sample, we found the internal consistency value of .72, evaluated by Cronbach's alpha.

- Competitive anxiety: the Brazilian version (Fernandes et al., 2013) made from the reduced version of the Competitive State Anxiety Inventory (CSAI-2R) (Cox, Martens, \& Russell, 2003) was used to evaluate the competitive anxiety of athletes. CSAI-2R consists of 16 items that measure three subscales: cognitive anxiety (e.g. "I am concerned about losing weight"); somatic anxiety (e.g. "I feel my body tense"); and self-confidence (e.g. "I feel self-confident"). The score for each subscale was the sum of the responses of the items of each factor, divided by the respective number of items. The frequency dimension of CSAI-2R was adopted as a criterion for assessing competitive anxiety, which is arranged on a Likert scale of 7 points, ranging from 1 (never) to 7 (very often). The higher the score, the longer the athletes have presented the symptoms of competitive anxiety. The CSAI-2R was validated for Brazilian athletes and showed high psychometric properties (Fernandes et al., 2013). In the present sample, we identified internal consistency of .77 (evaluated by Cronbach's alpha).

- Coping strategies: the Athletic Coping Strategies Inventory - ACSI (Serpa \& Palmeira, 1997) was used to evaluate coping strategies in the sports field. 
ACSI consists of 28 items on a 4-point Likert scale, ranging from "almost never" to "almost always." The ACSI is arranged in seven sub-scales that assess the following psychological skills: 1. maximum performance under pressure; 2. no worries; 3. coping with adversity; 4. concentration; 5. goal formulation; 6. confidence and motivation for achievement; and 7 . trainability or availability for learning from training. Each subscale contains four items and the absolute values recorded in each one are added together and divided by four to obtain an average value for each subscale. The values of the items in the concern subscale and two of the items in the training subscale (3 and 10) are inverted. The ACSI was validated for the Brazilian athlete population (Serpa \& Palmeira, 1997), obtaining good psychometric indexes. In the present sample, we found the value of .78 for internal consistency, evaluated by Cronbach's alpha.

- Anthropometry: a portable digital scale (Tanita ${ }^{\circledR}$ BC-601, São Paulo, Brazil) and a portable stadiometer (Welmy ${ }^{\circledR}$, Santa Bárbara do Oeste, Brazil) were used to determine body mass and height. The body mass index (BMI) was determined by the ratio between body mass $(\mathrm{kg})$ and square height $(\mathrm{m})$. Skinfold thickness was measured through a Lange adipometer (Lange (C), Washington, USA), in order to estimate body density. We used the predictive equation proposed by Slaughter et al. (1988) and Jackson and Pollock (1978) respectively created for teenagers and adults. Relative body fat was estimated by the Siri equation (1956).

\subsection{Procedures}

The procedures adopted in this study obey the Criteria of Ethics in Research with Human Beings, according to Resolution No. 466/12 of the National Health Council. The study is part of the institutional project approved by the Research Ethics Committee (Opinion No. 59783316.4.0000.5208). Initially, we contacted the management of the clubs to request authorization for data collection, which were carried out in the clubs' facilities, during the established days and by the team. It means that only the athletes of a team answered the questionnaires at the same time in a private room, in the absence of the coaches. All of them answered the questionnaires before their trainings. No communication between participants was allowed during data collection. The order of the questionnaires was randomized 
among the participants, and it took them about 30 minutes to complete the questionnaires.

\subsection{Data analysis}

Asymmetry (ISkI < 3.0), kurtosis (IKul < 10) and Mardia coefficient for multivariate kurtosis were carried out to assess the distribution of the research data. In addition, the Kolmogorov-Smirnov test was used to evaluate the data normality assumptions. Homoscedasticity was verified through the Levene test, and data sphericity was checked through the Mauchly test. In case the latter assumption had been violated, the Greenhouse-Geisser correction was adopted. Thus, mean and standard deviation were used to describe the investigation variables. We adopted the confirmatory factor analysis (CFA) to evaluate the factorial structure of the psychometric instruments used in this study. The following approaches were used to evaluate the CFA adjustment: root mean square error of approximation (RMSEA), goodness-of-fit index (GFI), adjusted goodness-of-fit index (AGFI) and Tuker-Lewis index (TLI).

We followed Pearson's correlation to relate the variables of the study. Then, we performed the structural equation modeling (SEM) using Amos 21.0 software to analyze the relationships of the research variables. The RBED value was used as a dependent variable and the coping strategies as a mediating variable. Maximum likelihood estimation was adopted, using the critical ratio (CR) as an indicator to estimate the chances of reproducing the observed data. We used the bootstrapping technique (1,000 samples) to test the effect of the mediating variables. Moreover, the outliers identified by means of Mahalanobis squared distance $\left(D^{2}\right)$ were excluded, corroborating the theoretical assumptions to perform the structural equation modeling (SEM). To assess the model adjustment, we followed the RMSEA, GFI, AGFI and TLI indicators. As model adherence indicators, the values pointed out by Hair, Hult, Ringle, and Sarstedt (2014) were adopted: .008 for RMSEA and .90 for the other adjustment indicators. For the conduction of SEM, a $5 \%$ significance level was adopted. It should be observed that chronological age and fat percentage were statistically controlled (inserted as covariates), according to the findings of other scientific investigations (Fortes et al., 2015; Fortes, Kakeshita et al., 2014). 


\section{Results}

Table 3.1 displays the descriptive data of this study. Statistically significant correlations between the research variables were identified, including the assumptions for conducting SEM. We highlight the significant $(p<.05)$, moderate $(r>.40)$ and positive correlation of EDDS with CSAI-2R $(r=.62)$, and negative ones with ACSI $(r=-.45)$. CSAI-2R was associated significantly $(p<.05)$ and negatively with ACSI $(r=-.77)$.

Table 3.1. Descriptive values (mean and standard deviation) and intercorrelation between the variables of the study.

\begin{tabular}{lccccc}
\hline & Mean & SD & EDDS & CSAI-2R & ACSI \\
\hline EDDS & 36.41 & 11.89 & - & $.62^{*}$ & $-.45^{*}$ \\
\hline CSAI-2R & 29.08 & 12.17 & & - & $-.77^{*}$ \\
\hline ACSI & 47.54 & 16.02 & & & - \\
\hline BMI $\left(\mathrm{kg} / \mathrm{m}^{2}\right)$ & 22.73 & 1.37 & & & \\
\hline FP (\%) & 18.90 & 7.54 & & & \\
\hline WTR (hours) & 10.19 & 1.11 & & & \\
\hline Age (years) & 18.15 & 1.68 & & & \\
\hline
\end{tabular}

Note: $\mathrm{SD}=$ standard deviation; EDDS = Eating Disorder Diagnostic Scale; CSAI-2R = Competitive State Anxiety Inventory; ACSI = Athletic Coping Strategies Inventory; BMI = Body Mass index; FP = fat percentage; WTR = weekly training routine; ${ }^{*} p<.05$.

Table 3.2 displays the statistical data on confirmatory factor analysis regarding the psychometric instruments used in this study. The findings indicated that the factorial structure of all the questionnaires was confirmed. 
Table 3.2. Goodness-of-fit indexes of the confirmatory factor analysis of the instruments used in the present study.

\begin{tabular}{lcccc}
\hline Instrument & RMSEA & GFI & AGFI & TLI \\
\hline Eating Disorder Diagnostic Scale & .007 & .91 & .94 & .93 \\
\hline Competitive State Anxiety Inventory & .006 & .94 & .95 & .92 \\
\hline Athletic Coping Strategies Inventory & .008 & .89 & .91 & .90 \\
\hline
\end{tabular}

Note: RMSEA = root mean square error of approximation; GFI = goodness-of-fit index; AGFI = adjusted goodness-of-fit index; TLI = Tucker-Lewis index.

Table 3.3 shows that the study variables had good adherence to the structural equation model $(\mathrm{SEM}=.007 ; \mathrm{GFI}=.90 ; \mathrm{AGFI}=.92 ; \mathrm{TLI}=.93 ; \mathrm{CR}=2.56)$.

Table 3.3. Goodness-of-fit indexes of the Structural equation modeling.

\begin{tabular}{lcccc}
\hline RMSEA & GFI & AGFI & TLI & CR \\
\hline .007 & .90 & .92 & .93 & 2.56 \\
\hline
\end{tabular}

Note: RMSEA = root mean square error of approximation; GFI = goodness-of-fit index; $\mathrm{AGFI}=$ adjusted goodness-of-fit index; TLI = Tucker-Lewis index; $C R=$ critical ratio.

The general model explained $42 \%$ of the RBED variance (Figure 3.1, $F\left({ }_{3,736}\right)=$ 56.08; $p=.01)$. It should be noted that the results did not indicate the missing data. They revealed a direct relationship between competitive anxiety (CSAI-2R) and $\operatorname{RBED}(\operatorname{EDDS})\left(\mathrm{F}_{(2,737)}=41.38 ; \mathrm{p}=.01\right)$ and also demonstrated that coping strategies (ACSI) enhanced the relationship between competitive anxiety (CSAI$2 R)$ and RBEDs (DES) $\left(F_{(3,736)}=45.75 ; p=.01\right)$.

The results of the bootstrapping technique were significant $\left(F_{(3,736)}=51.29\right.$; $p=.01 ; 1 C 95 \%=0.57-0.65)$, indicating that the mediating effects represent an empirical approximation of the original population distribution (male Brazilian athletes). 


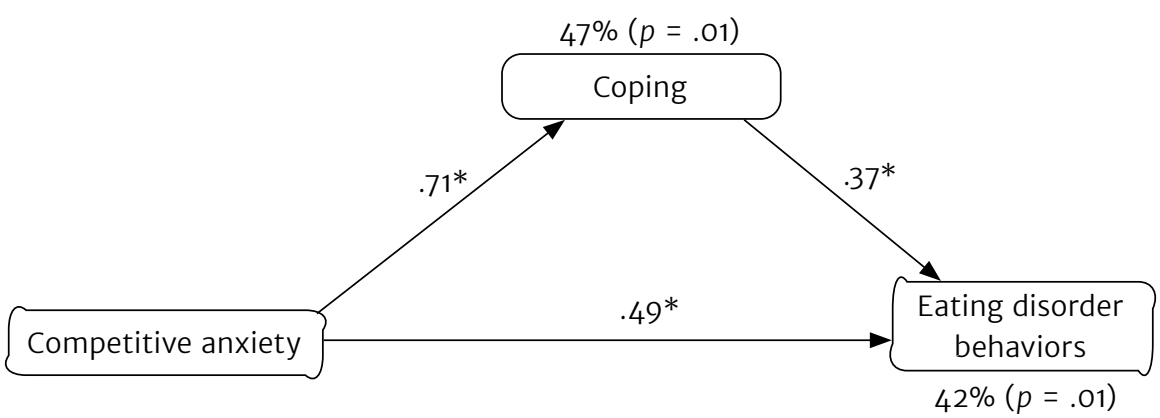

Figure 3.1. Structural Equation Modeling of the mediating role of coping in the relationship between competitive anxiety and eating disorders in male athletes.

\section{Discussion}

This study's premise was to analyze the mediation of coping strategies between competitive anxiety and RBED in Brazilian male athletes. Considering the practical aspect, the analysis performed in this investigation is important to implement prevention programs and/or psychological intervention, in order to reduce the incidence of eating disorders in this population.

Scientific studies have demonstrated that approximately $20 \%$ of male athletes adopt RBED with the objective of reducing body mass (Durguerian et al., 2016; Papathomas \& Petrie, 2014). It seems that approximately $1 / 4$ of male athletes are vulnerable to the development of eating disorders. The probable cause for RBED development in these athletes is the high internal and external pressure they suffer, which may be a risk for these behaviors to become addictive and pathological (Oberle, Watkins, \& Burkot, 2018). Since athletes usually associate body mass reduction with performance optimization in competitions (Papathomas \& Petrie, 2014), some of them may embrace RBED, aiming to enhance competitive results. Moreover, athletes can increase the level of competitive anxiety when they feel under pressure (Fortes, Lira, Lima, Almeida, \& Ferreira, 2016).

The structural equation model has pointed out a direct relationship between competitive anxiety and RBED. These findings indicated that stress perception during competitive events and negative thoughts about competitive performance were associated with the triggering of RBED in Brazilian male athletes. Such results 
can be explained through the theoretical model regarding the etiology of RBED in athletes (Petrie \& Greenleaf, 2007). It postulates that the stressing demand of the competitive environment (training, performance results, and competitions) is highly influenced by the context where the athlete is inserted. This demand may increase the risk of psychological problems (e.g., RBED, anxiety, depression). These findings are in line with the literature, which shows that athletes with higher levels of anxiety are more susceptible to adopting RBED (Fortes, Ferreira et al., 2014; Vardar et al., 2007). Thus, it seems that athletes who are too concerned with competitive performance or those who demonstrate higher activation of the autonomic nervous system (e.g., heart rate, sweating, pupil dilation etc.) in stressful situations (e.g., competition) are usually more vulnerable to adopting RBED (Vardar et al., 2007). Perhaps, athletes relate the use of appetite suppressants, laxatives and/or diuretics to the enhancement of competitive performance. This association may be an attempt to decrease the frequency of negative mental imaging of situations possibly occurring during competitions, which cautiously may explain the findings of this study.

The current literature demonstrates that coping strategies can act as a protective element against RBED triggering (Chapman \& Woodman, 2016; Fortes et al., 2015; Thompson \& Sherman, 2014). The structural equation model pointed out that, in fact, coping strategies mediated the relationship between competitive anxiety and RBED, corroborating the hypotheses of the research of Fortes et al. (2015). This result indicates that the type of coping (e.g., confrontation or avoidance) can determine the adoption of RBED in anxious athletes. For example, an athlete who demonstrates a high level of competitive anxiety may not trigger RBED if he adopts a confrontation coping strategy. On the contrary, an anxious athlete may be susceptible to adopting RBED if he uses an avoidance coping strategy. Moreover, an athlete who does not use any type of coping, but is anxious in a competitive situation, may trigger RBED. Nevertheless, it is worth mentioning that these are hypotheses, since the results of the structural equation model performed do not allow this type of conclusion. Thus, studies that seek to analyze the relationship between coping strategies and RBED in athletes need to be developed, in order to better understand this phenomenon.

Although this study points out unprecedented and important results, it has limitations. Since we used self-reported instruments as assessment tools, the 
results may not reflect the context analyzed, because the responses were subjective. It is worth noting that the ACSI scale was adapted to the Portuguese population (Serpa \& Palmeira, 1997). Portuguese is the language spoken in Brazil and Portugal, but these countries have significant cultural differences and also small changes in their own writing. In this sense, the use of such a psychometric instrument in this study may have influenced the results obtained. However, in order to ensure the validity of the data obtained, confirmatory factor analysis (CFA) was carried out for all the questionnaires, and the findings indicated acceptable adjustment rates, which reduces the possibility of invalidating the aforementioned instruments. Another limitation is that we used only the total score of the instruments, making impossible the mediating role of ACSI-28 subscales in the association between anxiety and RBED. In addition, this study was restricted to the evaluation of psychological variables of athletes in just one moment (cross section), which does not characterize the real relationships of cause and effect between the variables. Thus, future investigations should use a prospective approach with the athletes, besides crossing the previously described psychological variables with the performance levels during the season.

In spite of the limitations, we believe the results of this study are extremely important for professionals working in the sports context. Moreover, such findings may help to prepare programs of prevention and/or treatment of RBED in Brazilian male athletes.

\section{Conclusion}

It is concluded that coping can be considered a determining psychological variable in the relationship between competitive anxiety and RBED, acting as an enhancer of the negative effects of anxiety on RBED. We suggest further investigations with male Brazilian athletes to confirm the findings of this study (external validity). Furthermore, it is recommended the construction of an etiological model of RBED for Brazilian athletes of both sexes. The practical results of this study are in the possibility of sports professionals, more specifically, sports psychologists, to develop interventions that make it possible to decrease the level of competitive anxiety and/or enhance the development of coping strategies to reduce the triggering of RBED in Brazilian male athletes. 


\section{References}

Chapman, J., \& Woodman, T. (2016). Disordered eating in male athletes: A metaanalysis. Journal of Sports Science, 34(2), 101-109. doi:10.1080/02640414.2015. 1040824

Cox, R. H., Martens, M. P., \& Russell, W. D. (2003). Measuring anxiety in athletics: The revised competitive state anxiety inventory-2. Journal of Sport and Exercise Psychology, 25(4), 519-533.

Durguerian, A., Bougard, C., Drogou, C., Sauvet, F., Chennaoul, M., \& Filaire, E. (2016). Weight loss, performance and psychological related states in high-level weightlifters. International Journal of Sports Medicine, 37(3), 230-238. doi:10.1055/s-0035-1555852

Fernandes, M. G., Nunes, A. S., Raposo-Vasconcelos, J., Fernandes, H. M., \& Brustad, R. (2013). The CSAl-2: An examination of the instrument's factorial validity and reliability of the intensity, direction and frequency dimensions with Brazilian athletes. Journal of Applied Sport Psychology, 25(4), 377-391. doi:10.1080/10413200. 2012.744780

Filaire, E., Rouveix, M., Pannafieux, C., \& Ferrand, C. (2007). Eating attitudes, perfectionism and body-esteem of elite male judoists and cyclists. Journal of Sports Science and Medicine, 6(1), 50-57.

Fortes, L. S., Almeida, S. S., \& Ferreira, M. E. C. (2014). Influence of psychological, anthropometric and sociodemographic factors on the symptoms of eating disorders in young athletes. Paidéia, 24(57), 21-27. doi:10.1590/1982-43272457201404

Fortes, L. S., Almeida, S. S., \& Ferreira, M. E. C. (2016). Psychometric analysis of Disordered Eating in Sports Scale (DES). Paidéia, 26(1), 171-180. doi:10.1590/198243272664201603

Fortes, L. S., Ferreira, M. E. C., \& Almeida, S. S. (2014). Are inappropriate eating behaviors and anxiety related with track and field in adolescent athletes? Revista de Nutrição, 23(3), 311-319. doi:10.1590/1415-52732014000300005

Fortes, L. S., Ferreira, M. E. C., Oliveira, S. M. F., Cyrino, E. S., \& Almeida, S. S. (2015). A socio-sports model of disordered eating among Brazilian male athletes. Appetite, 92(1), 29-35. doi:10.1016/j.appet.2015.05.005 
Fortes, L. S., Kakeshita, I. S., Gomes, A. R., Almeida, S. S., \& Ferreira, M. E. C. (2014). Eating behaviours in youths: A comparison between female and male athletes and non-athletes. Scandinavian Journal of Medicine \& Science in Sports, 24(1), e62-e68. doi:10.1111/sms.12098

Fortes, L. S., Lira, H. A. A. S., Lima, R. C. P., Almeida, S. S., \& Ferreira, M. E. C. (2016). Mental training generates positive effect on competitive anxiety of young swimmers? Revista Brasileira de Cineantropometria e Desempenho Humano, 18(3), 353361. doi:10.5007/1980-0037.2016v18n3p353

Gapin, J. I., \& Petruzzello, S. J. (2011). Athletic identity and disordered eating in obligatory and non-obligatory runners. Journal of Sports Sciences, 29(10), 1001-1010. doi:10.10 80/02640414.2011.571275

Gomes, A. R., Martins, C., \& Silva, L. (2011). Eating Disordered Behaviors in Portuguese athletes: The influence of personal, sport, and psychological variables. European Eating Disorders Review, 19(1), 190-200. doi:10.1002/erv.1113

Haase, A. M. (2011). Weight perception in female athletes: Associations with disordered eating correlates and behavior. Eating Behaviors, 12(1), 64-67. doi:10.106. eatbeh.2010.09.004

Hair, J. F., Hult, G. T. M., Ringle, C. M., \& Sarstedt, M. (2014). A Primer on Partial Least Squares Structural Equation Modeling (PLS-SEM). Thousand Oaks: Sage.

Jackson, A. S., \& Pollock, M. L. (1978). Generalized equations for predicting body density of men. British Journal of Nutrition, 40, 497-504.

Krentz, T. M., \& Warschburger, P. (2013). A longitudinal study investigation of sportsrelated risk factors for disordered eating in aesthetic sports. Scandinavian Journal of Medicine \& Science in Sports, 23(3), 303-310. doi:10.1111/j.1600-0838.2011.01380.x

Kurimay, D., Pope-Rhodius, A., \& Kondric, M (2017). The relationship between stress and coping in table tennis. Journal of Human Kinetics, 55(1), 75-81. doi:10.1515/ hukin-2017-0007

Martens, R., Vealey, R. S., \& Burton, D. (1990). Competitive anxiety in sport. Champaign, IL: Human Kinetics.

Michou, M., \& Costarelli V. (2011). Disordered eating attitudes in relation to anxiety levels, self-esteem and body image in female basketball players. Journal of Exercise and Science Fitness, 9(2), 109-115. doi:10.1016/S1728-869X(12)60006-9 
Oberle, C. D., Watkins, R. S., \& Burkot, A. J. (2018). Orthorexic eating behaviors related to exercise addiction and internal motivations in a sample of university students. Eating and Weight Disorders, 23, 67-74. doi:10.1007/s40519-017-0470-1

Papathomas, A., \& Petrie, T. (2014). Editorial: Towards a more sophisticated approach to eating disorders in sport research. Psychology of Sport \& Exercise, 15, 675-679. doi:10.1016/j.psychsport.2014.06.006

Peden, J., Stiles, B. L., Vandehey, M., \& Diekhoff, G. (2008). The effects of external pressures and competitiveness on characteristics of eating disorders and body dissatisfaction. Journal of Sport \& Social Issues, 32(4), 415-429. doi:10.1177/ 0193723508325638

Petrie, T. A., \& Greenleaf, C. (2007). Eating disorders in sport. From theory to research to intervention. In G. Tenenbaum \& R. Eklund (Eds.), Handbook of sport psychology (3rd ed., pp. 352-378). Hoboken, NJ: Wiley.

Pons, J., Viladrich, C., Ramis, Y., \& Polman, R. (2018). The mediating role of coping between competitive anxiety and sport commitment in adolescent athletes. The Spanish Journal of Psychology, 21, e7. doi:10.1017/sjp.2018.8

Scoffier, S., Maiano, C., \& D'Arripe-Longueville, F. (2010). The effects of social relationships and acceptance on disturbed eating attitudes in elite adolescent female athletes: The mediating role of physical self-perceptions. International Journal of Eating Disorders, 43(1), 65-71. doi:10.1002/eat.20597

Serpa, S., \& Palmeira, A. L. (1997). ACSI 28: Estudo das experiências desportivas. Lisboa: Laboratório de Psicologia do Desporto, Faculdade de Motricidade Humana, Universidade Técnica de Lisboa.

Siri, W. E. (1956). The gross composition of the body. In C. A. Tobias \& J. H. Lawrence (Eds.), Advances in biological and medical physics (pp. 239-280). New York: Academic Press.

Slaughter, M. H., Lohman, T. G., Boileau, R., Hoswill, C. A., Stillman, R. J., \& Yanloan, M. D. (1988). Skinfold equations for estimation of body fatness in children and youth. Human Biology, 6o(3), 709-723.

Thompson, R. A., \& Sherman, R. (2014). Reflections on athletes and eating disorders. Psychology of Sport \& Exercise, 15(6), 729-734. doi:10.1016/j.psychsport.2014.06.005 Vardar, E., Vardar, S. A., \& Kurt, C. (2007). Anxiety of young female athletes with disordered eating behaviors. Eating Behaviors, 8(2), 143-147. 
Wadey, R., Podlog, L., Hall, M., Hamson-Utley, J., Hicks-Little, C., \& Hammer, C. (2014). Reinjury anxiety, coping, and return-to-sport outcomes: A multiple mediation analysis. Rehabilitation Psychology, 59(3), 256-266. doi:10.1037/a0037032

\section{Authors notes}

Leonardo de S. Fortes, Post-Graduate Program in Cognitive Neuroscience and Behavior and Associated Graduate Program in Physical Education (UPE/UFPB), Federal University of Paraíba (UFPB); José Roberto A. do Nascimento Junior, Post-Graduate Program in Physical Education (PPGEF), Federal University of Vale do São Francisco (UNIVASF); Gabriel L. M. Freire, Post-Graduate Program in Physical Education (PPGEF), Federal University of Vale do São Francisco (UNIVASF); Maria Elisa C. Ferreira, Associated Post-Graduate Program in Physical Education (UFV), Federal University of Juiz de Fora (UFJF).

Correspondence concerning this article should be addressed to José Roberto de Andrade do Nascimento Junior: Av. José de Sá Maniçoba, S/N, Centro, Petrolina, PE, Brazil. CEP 56304-205.

E-mail: jroberto.jrs01@gmail.com 